\title{
Investigating special education teachers' knowledge and skills: Preparing general teacher preparation for professional development
}

\author{
David R. Byrd ${ }^{1}$ and Melina Alexander ${ }^{2}$ \\ ${ }^{1}$ Weber State University, Moyes College of Education, United States (ORCID: 0000-0002-1726-3320) \\ ${ }_{2}^{2}$ Weber State University, Moyes College of Education, United States (ORCID: 0000-0001-9198-3732)
}

\begin{abstract}
Including students with special needs in the general education classroom requires that teachers adapt their approaches to teaching to meet all students' needs. However, general education teachers are not always fully aware how best to serve special populations. This study examines what skills and knowledge special education educators feel that general education teachers and teacher candidates need in order to work with students with special needs in the inclusive environment. The researchers interviewed twenty special educators to ascertain which skills and knowledge are most commonly cited as vital to successful general education teacher/student with special needs interactions. Findings suggest that teacher education and professional development programs can benefit by providing a continuum of learning opportunities in three important areas. General educators should: first, make and carry out informed decisions, based on proper assessments data; second, develop appropriate understanding and compassion for students with special needs and their situations and third, learn to foster effective communication in and out of the classroom with all parties involved in educating this specific group of students.
\end{abstract}

Keywords: General education; Teacher education; Inclusion; Effective teaching; Teacher communication

Article History: Submitted 8 January 2020; Revised 20 April 2020; Published online 24 April 2020

\section{Introduction}

In today's education climate, the responsibility for teaching students with special needs no longer lies exclusively with special education (SPED) teachers. With the passage of the Individuals with Disabilities Education Improvement Act (IDEIA), the 'least restrictive environment' (LRE) of the general education classroom has been positioned as the optimal learning space (O'Connor, Yasik, \& Horner, 2016). This change means that the educational philosophy has moved towards inclusion, where teachers at all levels and content areas are required to interact and work with students with special needs on a regular basis (Saloviita, 2018; Turnbull, Turnbull, \& Weymeyer , 2010; US Department of Education, 2012). This push for including students with disabilities in the general education classroom has been seen internationally as well, not only in the area of education, but also by organizations like the United Nations, the World Bank and Council of the European Union (Doulkeridou, et al., 2011; Miskovic \& Curcic, 2016; Ozel, Zhagan, Nor, Daud, \&

Address of Corresponding Author

David Byrd, Weber State University, 1351 Edvalson Street, Dept. 1304, Ogden, UT 84408-1304, the USA.

$\triangle$ davidbyrd@weber.edu

How to cite: Byrd, D. R. \& Alexander, M. (2020). Investigating special education teachers' knowledge and skills: Preparing general teacher preparation for professional development. Journal of Pedagogical Research, 4(2), $72-82$. 
Ali, 2017; Saloviita, 2018). Inclusive education has gained the status of international law (Ozel, et al., 2017).

Although students with special needs have been placed in general education classrooms for many years, numerous studies have suggested that many general education teachers are not fully aware of what needs to happen to make the inclusive setting a successful environment (Bruggnick, Goel, \& Koot, 2015; Leko, Brownell, Sindelar, \& Kiely, 2015; Smit \& Humpert, 2012). Teacher preparation programs (TPPs) and professional development (PD) can provide educators with skills to create opportunities for all students to learn. However, most pre- and in-service programs still struggle to inform in a way that provides general educators with the tools needed to interact effectively with students with special needs in a general education classroom (Ingvarson et al., 2014; Rock et al., 2016). The methods of working with students with special needs are often addressed in these programs, but educators still seem to need help answering the question, "What knowledge and skills must be developed among teachers so that they can work effectively with students with special needs?" (cf Harper \& de Jong, 2009).

\subsection{Educational Context}

As suggested above, the landscape of the classroom is changing. These spaces consist of an everincreasing body of students with special needs, ranging from learning and/or behavioral challenges and sometimes with linguistically and culturally varied backgrounds as well (Forte \& Flores, 2014; Rock, et al., 2016). Some of these changes have been mandated by federal, state, and/or local educational agencies, which dictate that teachers must be well prepared to teach diverse learners, including students with disabilities. Students with disabilities are guaranteed a free and appropriate public education (FAPE), in the LRE, according to IDEIA. The concept of LRE means that students with disabilities will be educated with their non-disabled peers to the greatest extent possible based on individual needs. This concept, often called inclusion, is defined as serving students with various levels of abilities or disabilities in the general education classroom with in-class support (Cushner, McClellend, \& Safford, 2015). However, federally mandated changes created a call for 'highly qualified teachers.' This generated a pressure to educate teacher candidates in a 'one-size-fits-all' manner which did not allow for the diverse thinking required to meet the needs of classrooms full of students who do not fit the standardized norm (Brownell, Bishop, \& Sindelar, 2018; Kent \& Giles, 2016). Exacerbating this issue was the passage of the Every Student Succeeds Act (ESSA). ESSA shifted focus from federal to state decision-making authority regarding teacher certification, generating concerns that standards will be further reduced and teacher development practices diluted (Rock, et al., 2016; US Department of Education, 2015). With the pressure to meet state and federal mandates, TPP and PD may minimize focus on best practices for working with students with disabilities in the general education setting; this should not be the case.

More specifically, preparing teachers for working with students in their LRE is critical, as it is one of the few offerings that provide key information on managing student behavior, assessments and professional interaction expectations (Flower, McKenna, \& Haring, 2017; Friend, Embury, \& Clarke, 2015; Kent \& Giles, 2016; Leko et al., 2015). In today's schools, inclusive environments emphasize cooperative and coordinated practices among educators to inform better teaching for all students (Leko et al., 2015). This includes co-teaching between special and general educators with a goal to design specific instruction for students (Friend, 2015; Friend et al., 2015), and peer teaching between students in the inclusive classroom (Kent \& Giles, 2016) The goal of these practices is to make certain that all stakeholders are involved in creating an LRE for students with special needs. In addition, researchers have suggested that this reconceptualization of LRE moves beyond just the school to include stakeholders in the community around the school, including governing bodies for the school and the community (Cushner, McClellend, \& Safford, 2015; O'Connor et al., 2016; Pavlović, 2016). Ideally, TPP courses and on-going PD would address how to make all these interactions a reality. 


\subsection{Rationale of the Study}

The opinions and expertise of practicing special education professionals are largely missing from the literature that informs teaching practices in the inclusive classroom (Bruggink et al., 2015; Jones, Youngs, \& Frank, 2013; Shevlin, Winter, \& Flynn, 2013). The goal of this study was to give these professionals a voice in expressing the ideas and approaches to inform their general education counterparts. In order to address this gap, the guiding principle for the present study was to determine and describe what aspects of teaching special education educators feel that general education teachers need in order to work successfully with students with special needs in the inclusive classroom.

\section{Method}

\subsection{Research Design}

Qualitative methodology was determined to be appropriate for the present study, which allows for the flexibility necessary to analyze the thoughts and opinions of the participants. As the study recounts the experience of a group of individuals and their lived experience, a phenomenological approach to analyze the data was used (Creswell, 2013). Phenomenology describes what the participants have in common as they experience the phenomenon with an eye towards describing a universal essence for the group (Creswell, 2013, p. 76). Grounded theory provided the framework to structure the emerging themes found within the data source documents (Creswell, 2013; Merriam \& Grenier, 2019). Creswell explains that a grounded theory study "has 'movement' or some action that the researcher is attempting to explain" (p. 85). Merriam and Grenier state that this approach strives to derive meaning from the data and is localized in that it deals with "particular real-world situations" (p. 9). As a descriptive study, this project was an examination of the knowledge base of special education teachers; therefore, it was grounded in the descriptions of interview data.

As is typical of qualitative research, the data in the present study were analyzed recursively and inductively. To this end, the researchers implemented a constant comparison method, which is one characteristic of grounded theory approach that aids in forming categories and summarizing the content of each category (Creswell, 2013). Beginning with a subset (five of 20 interviews), the researchers independently read each interview three times, marking topics related to inclusive teaching, first listing broad topics to identify emerging themes, and again to refine those themes. After these readings, the researchers came together to discuss their findings. First, commonalities in the coding were identified, then discrepancies were discussed until consensus was achieved across all themes. Codes among the themes were then determined together and a similar process of refining followed. Finally, after the themes and codes were identified, the remainder of the interviews were examined to provide results below.

\subsection{Participants}

Eighty-three special education professionals were interviewed over a two-year period. For this study, twenty of those interviews were randomly selected by choosing every fourth participant's data, which was determined to be a robust sampling (Creswell, 2013). Initial contact for participation in the study was made utilizing an email to special educators at school districts near the research site. However, over time, participants independently provided names of colleagues whom they felt would be interested in taking part in the study as well. Therefore, of this group of 20, sixteen were educators from local districts (Utah), and four were from various areas in the western US (Arizona, California, Hawaii, Nevada). Using suggested 'others,' the participant pool grew to include special educators outside the classroom situation, including self-contained classroom teachers, co-teachers with general educators, educational coaches, and one retired teacher. This diversity provided a greater richness in the data. Further, the respondents ranged from elementary $(n=13)$ to secondary $(n=7)$. Sixteen of the participants were female, and four were male, with ages ranging from 22 to 60 . 


\subsection{Procedures}

Semi-structured interviews were conducted face-to-face, in-person, or via Skype, using the questions found in Table 1 as a guide. The semi-structured nature of the interviews encouraged participants to expand on answers already given and allowed examination of other related ideas. The interviews were recorded and transcribed and given to the interviewees to check for accuracy. Institutional Review Board approval was obtained.

The questions for the survey were adapted from previous work done by Harper and de Jong (2009) but edited with an eye towards special education. The researchers adapted questions, and they sought feedback from colleagues. After initial changes, the researchers spoke with a small sample of special educators who volunteered to be interviewed and provide additional comments. Final modifications to the questions were made at this time, which resulted in the question set found in Table 1.

Table 1

Special education teacher interview/survey questions

1. What do special education teachers know and do that is different from what general education teachers know and do in (and out of) the classroom?

2. In addition to knowledge and skills, what is required of a special education teacher that might not be expected of general education classroom teachers?

3. What traits and/or actions set apart an excellent special education teacher from a good special education teacher?

4. What is most important for teachers in inclusive classes to know/do in order to work effectively with learners with special needs?

5. Is there anything else that you would like to add?

\section{Results}

Pursuant to the data analysis procedures described in the previous section, patterns in the participants' responses allowed for examination, leading to specific tags that conceptualized the guiding principle for this study: to describe what aspects of teaching that special educators feel that general educators need to know to work successfully with students with special needs. Three broad categories emerged, namely, 1) core knowledge, 2) key dispositions, and 3) essential skills. Due to space limitations, the analysis will focus on these three major categories and the top two sub-categories in each area. It must be emphasized that the categories are not mutually exclusive, with some aspects of the findings overlapping.

\subsection{Core Knowledge}

\subsubsection{Assessment and data collection}

The top two themes in this category were closely related, but there were a few areas of divergence. Respondents first indicated the importance of assessment and the necessity of using data to monitor student progress. Second, they highlighted the use of these assessments and progress monitoring data to inform key stakeholders of student progress and educational needs.

Participants doubted the vital role of assessing students. They also spoke to data collection procedures informing assessment outcomes. One secondary special education teacher spoke of "collecting data through multiple methods of assessment to see if the student is making progress." Another elementary special education teacher simply said that there were "a lot more assessments [in special education]."

Almost all the participants spoke about their specialized knowledge of assessing students, emphasizing that this skill was beyond what is expected of the general education teacher. Several respondents spoke specifically about the multiple modes of assessment required for students with 
special needs. At the same time, several participants emphasized the need to assess students frequently in order to determine if student learning is progressing. As one teacher stated, "there is (sic) a lot more assessments and data that must be collected." Mainly, this aspect of core knowledge was discussed in relation to the "outrageous amount of paperwork" required of special educators. Some of the respondents discussed how special education teachers "do a lot more intensive data collection (than their general education peers)" and that they "are expert in data collection."

Related to the collection of data and assessment was the second theme, special educators use data to inform all stakeholders. For the special educator, this requirement was simply part of their job, however, also required by law (IDEIA, P.L. 108-444). Common was the idea expressed by an elementary educator, "special education teachers are experts at analyzing data and knowing how to adjust their instruction to accommodate and reach out to all learners." Specifically, several participants spoke about using data to inform the creation of individualized education plans (IEPs), "The data and the observations are used to help build effective IEPs." Similarly, respondents discussed a more overarching use of data, which another elementary teacher summed up as follows:

The SPED teacher is responsible and accountable for ALL of the documents contained in the students' SPED files. That means that we keep track of at-risk and referral documents and who needs to sign them and make sure (that) the dates are correct. We also track the consent to test forms and then keep track of when the consent is returned and determine the 45 school day period of which we have to test, making sure all related servers (speech, OT [occupational therapy], adaptive p.e. [physical education] providers are aware of their testing responsibilities and when those are completed). Keep all testing protocols, either academic, cognitive, behavioral, adaptive, motor, in the file. Complete the eligibility, placement, and evaluation forms, write IEP goals according to the data, testing accommodations, and service times.

The ability to collect data and assess effectively was a major issue in the identification of students who are struggling in the inclusive classroom and determining if and what types of services are needed to meet their needs. One participant pointed out that the data from the various assessments often lead to changes in the student's education or the teacher's instructional approach. Related, several of the special educators stressed how results from the frequent assessments could and should help determine adaptation in teaching approaches and adaptation of learning. The special educators in the study pointed out that they were readily available to act as resources to general education teachers in making important decisions, based on data from these various assessments.

\subsection{Key Dispositions}

\subsubsection{Understanding and compassion}

The next theme that manifested from the data was centered on teacher dispositions. Respondents indicated that special educators tend to possess dispositions uniquely expressed in their situation. It was interesting that these traits were mentioned when participants talked not only about special education teachers in general, but also when they described an excellent special educator. The two most frequently mentioned dispositions cited in the present data set were understanding and compassion for students with special needs, their disabilities and challenges that they face both in and out of school. These two traits will be dealt with together as they were frequently mentioned together or sequentially.

A basic tenet found in this sub-theme is that the special educators interviewed talked about meeting the student with special needs at their present ability level. A secondary special education teacher's statement summed up this point, "the teacher needs to be willing to meet her students where they are at, not where they should be." Further, the respondents spoke of "finding strengths of students (with special needs) to build on and help them learn." 
Similarly, a part of understanding this student population meant that the family situation must be understood as well. As one elementary special education teacher stated, "teachers must be willing to get the idea that their life at home is very different from our life. They come to school every day and start over." Whereas this latter statement could be considered an extreme situation, the frequency with which similar statements were made merits note. Several of the interviewees also reported on times that they acted outside of the school, helping students and families find medical, financial, or other types of assistance that would meet the family's needs and keep the student in school.

These types of actions highlight the second sub-theme, compassion. One respondent summed up the ideas behind this disposition when she stated, "teaching special education means having the heart for the students; you just can't apply for this job. You must have compassion." The respondents also spoke of advocating for students within the school by visiting other teachers and classrooms as situations mandated, as well as finding specific teachers who are willing to work with students with special needs, but "not overwhelming any one teacher." Teachers must possess a certain degree of understanding and compassion for their students in order to work successfully with them; however, the respondents in the present study suggest that these two dispositions are required at a higher level than would be expected of a general educator.

\subsection{Essential Skills}

\subsubsection{Curriculum and assignment adaptation}

In this study, two main areas of essential professional skills mentioned by special educators, adapting curriculum and assignments. First, the participants discussed generally how to make adaptations. One secondary teacher expressed this idea by suggesting that "special education teachers are expert in program modifications, adaptation, and teaching to individual need which is much different than general education teaching." The other application of this theme involved special education teachers explicitly providing help for their general education colleagues, suggesting ideas like, "if you are looking to modify a lesson or assignment, collaborate with the SPED teacher." Other participants proposed ideas that can help the general education teacher realize that the students with special needs require different accommodations to meet these needs. One special educator in an elementary situation stated this idea thusly,

Understand that accommodations are not cheating or not giving an unfair advantage. I think that's the biggest thing. We say that "Hey! You know what? This kid needs some extra time on this assignment. Or this kid needs this read to him, or can you move this kid into a quiet room? " And they say, "That's unfair!" Well, it's not necessarily that it's unfair. It is the way that they're going to be able to give you their best job or show you their best ability.

\subsubsection{Communication}

Predominantly interwoven in the responses to all the questions is the ability and need for communication, which focused mainly on the manner and with whom. Regarding the former idea, the various questions teased out various ways in which the communication can take place, ranging from electronic resources (like email, texts, etc.) to phone calls and finally to face-to-face communication. For the latter, an elementary special education teacher's statement expressed the ideas as,

An excellent special ed teacher must work well with administration, the school psychologist, speech and language pathologists, occupational therapists, general education teachers, staff and classified employees, and parents of students with disabilities. She must be professional in her communications and assessments. While she is a resource for others, she recognizes that others are a resource for her. In other words, she keeps everyone in the loop, communicating, and advocating for the needs of students with disabilities. 
The goal of all this communication with the various stakeholders was to design and carry out more effective teaching for students with special needs. Unfortunately, many of the participants explicitly expressed frustration at the lack of communication among educators and stated that this communication is predominantly unidirectional. One secondary special education teacher mentioned, "Although we (special education teachers) are trying to put supports into place, they'll (general educators) still come down and say, 'Can you help this kid on your prep period?' or 'Can you help this kid after school?' So, we are having to look at this situation to see how we can work together as a team to educate them on how to take care of that child."

\section{Discussion}

Categories discovered in the analysis of this study align with Harper and de Jong's (2009) results. Respondents in this study also indicated special education teacher expertise in three areas 1) core knowledge, 2) key dispositions, and 3) essential skills. These categories also reflect the emphases of the National Council for Accreditation of Teacher Education (NCATE). It is likely that this set of participants, who were employed in the US schools and, most likely, educated at US TPPs, which often follow the NCATE standards, tended to view their work through this lens (Rock, et al., 2016).

Two of the key core knowledge areas for educators, particularly special educators, are data collection and assessment with the former informing that latter (Feuer, Floden, Chudowsky \& Ahn, 2013; Rock et al., 2016). Data-driven decision making in education in the US has been a goal of education, since it became a formalized institution, and, as indicated by our respondents, reflects an increasingly larger focus (Mertler, 2014). Findings in this area suggest that the assessment plays out in two important ways in the classroom. The first outcome shows that assessment happening in the general education classroom was not enough to meet the requirements of students with special needs. Although the general education teacher may have a broad idea of how to assess students, the specifics of assessing students with special needs is not always part of that knowledge, especially if the general education teacher is not willing to make adaptations in assessments; a situation that was voiced by several participants. As assessments (and data collection) are part of a 'teacher's toolbox' in the classroom, it is essential that all teachers become aware of how to use this tool for all students present in their classroom (ElSaheli-Elhage \& Sawilowsky, 2016).

The second way that these results occur is in determining elegibility for special needs services. The respondents also indicated that their knowledge of assessment goes beyond the legal requirement of determining if a student is eligible for services (O'Connor et al., 2016). Assessment must also be frequently used after students receive special education services to determine educational progress and instructional needs. This finding corresponded with Miskovic and Curcic's (2016) idea that assessment knowledge is needed to inform instruction, not just to stream students into special programs. General education professionals need to work with their special education counterparts to make this happen.

Dispositions, or the professional attitude and conduct related to teaching (Notar et al., 2009), was particularly noted by the participants and were specifically noted as understanding and compassion, which could be seen as empathy. This reflects Carroll's (2012) definition, "dispositions indicate a teacher's tendency to act effectively on the behalf of the learning and well-being of his or her students" (p. 38). Likewise, these attitudes and beliefs can play an important role in the success of a classroom (Kent \& Giles, 2016) and help to create a supportive learning environment for students with special needs in inclusive settings (Friend, 2015; Rock et al., 2016). Further, the interviewees also indicated that these dispositions often led to student advocacy. Advocacy was reflected in their stated commitment to finding outside resources for students; this supports the idea that special (and general) educators will need to be successful with multiple roles to be effective with all students (Brownell et al., 2018).

The dispositions of understanding and compassion also reflect work done by Grskovic and Trzcinka (2011), who emphasized that teachers in specialized areas, like special education, need to 
have particular dispositions in working with a given population of students. Likewise, Kirwan and Roumell (2015) pointed out that each educational situation will demand certain teacher dispositions to come to the fore for educators to be successful with their students.

Next, the essential skill of curricular adaptations or modifications discussed by participants supports Harvey's (2019) statement that skills in teaching are "the ability to use content, professional, and pedagogical knowledge effectively and readily in diverse teaching settings in a manner that ensures that all students are learning" (ף. 1). Participants indicated that they were better prepared to determine needed instructional adjustments. These findings are not surprising as the literature is replete with studies indicating that general education teachers are not fully aware of ways to work with students with special needs in their classrooms (Bruggnick et al., 2015; O'Connor et al., 2016; Page \& Davis, 2016; Rock, et al., 2016; Shevlin et al., 2013). Neither the general pedagogical knowledge nor the knowledge of context of the general education teacher are enough to meet the diverse needs of these students in the classroom. Nevertheless, pedagogy can be enhanced through collaboration with special education professionals, both pre-service (Sharma \& Sokal, 2015) and in-service (Forte \& Flores, 2014). Rosenberg and Koehler (2015) suggest that the development of knowledge in teaching is socially constructed and dynamic, and ever reconstructing, meaning that it is imperative to work together as it will help both sets of teachers improve their skills and, eventually, outcomes for their students. Forte and Flores (2014) point out that such collaborative efforts, performed effectively, are perceived as beneficial for both groups and can result in stronger student performance. Friend (2016) suggested that teachers must move beyond just the idea of accommodations to "specially designed instruction" that ensures that all educators are doing and are accountable for what the student needs to succeed (p. 2).

Finally, respondents also indicated the importance of communication for special educators. This is understandable as communication is key in a variety of special educator roles and responsibilities. Friend et al. (2015) emphasized in the practice of co-teaching that both the general and special educators must work together to plan for and teach this student population effectively. They, along with Page and Davis (2016), stress that neither educator must be seen as being in a subordinate position in (or out of) the classroom. Further, Leko et al. (2015) discuss the need for all stakeholders in the education of students with special needs to communicate effectively and efficiently both in collecting and reporting data to the student, other educators, and family members. Rock et al. (2016) put forth the idea of a culture of 'we' that includes all stakeholders, which mandates a change in thinking that currently seems to be pervasive in education (p. 111).

\section{Conclusions}

The topics provided by the participants indicated that the major issues which lead to improved teaching for students with special needs were not too foreign to the general education teacher and could lead to a productive dialogue. For too many years, a metaphorical wedge has been leveraged between the general and special education classroom stemming largely from a significant lack of communication, as the participants have pointed out here and elsewhere (cf. Friend et al., 2015; Leko et al., 2015; Rock et al., 2016). Much of this miscommunication and misinformation could be addressed early in TPPs, as teacher educators can provide general education majors the chance to interact with special education majors in both course work and practica, thus providing them opportunities to communicate effectively. These same concepts and practices can be reemphasized during PD offerings throughout the career of educators. The core knowledge, key dispositions and essential skills found in this study do not vary so greatly among educators that they are not beyond the reach of any them. They may just need some guidance in seeing how to access them.

\section{Recommendations}

The goal of this study was to bring the voices of practicing special educators to the fore in relation to what they feel that general education teachers need in order to work successfully with students 
with special needs in the inclusive classroom. The data suggested some effective tools for developing the environment of 'we' called for by Rock et al. (2016) in K-12 classrooms. However, these tools could further help educators in both pre- and in-service programs as they work towards making the education of all teaching professionals a seamless continuum, instead of discrete point offerings, for the benefit of children with special needs. Table 2 summarizes the findings of the study, which can become beginning points of consideration for this continuum. A starting place for each area could be as summarized in Table 2.

Table 2

Summary of findings

\begin{tabular}{ll}
\hline \multirow{2}{*}{ Core knowledge } & Assessment \\
\cline { 2 - 2 } Key dispositions & Data \\
\hline \multirow{2}{*}{ Essential skills } & Understanding \\
\cline { 2 - 2 } & Compassionate \\
\hline
\end{tabular}

\subsection{Core knowledge}

We all assess and collect data and make decisions based on those data. A dialogue can be developed not only to show how assessment can be modified but also to explain explicitly why it needs modifying with the specific end goal stated. Similarly, there may need to be a reexamination in the current view of how a subject area can be taught and what is important to teach. It is not a call to dumb down a curriculum; rather, an opportunity to focus on vital issues and topics in the area. Finally, all educators are responsible for effective assessments and data collection.

\subsection{Key disposition}

Teachers tend to be nurturers. Working with students with special needs manifests this nurturing slightly differently. We can learn from each other the most effective methods of giving care to this population of students.

\subsection{Essential skills}

Although a content area specialty provides one type of expertise, there is much more to teaching than that knowledge. We can all learn from each other the most effective methods of adapting the curriculum to meet the needs of all students. And finally, all of this can be done through effective communication that must be multi-directional (among all stakeholders, including administration).

These issues can act as a springboard starting from the day a teacher candidate entered their program and continued throughout their careers. It is not necessarily asking for others to think outside the box; it is realizing that the box is bigger than previously considered by those involved in this endeavor.

\section{Limitations}

The findings of this study need to be seen in light of some limitations. As is true with any type of qualitative research, the findings of this study cannot necessarily be generalized to the population as a whole. Few studies have been done in the area of exploring and presenting voices of special educators as a whole. This study looked at special educator views in general. As such, the findings from this study have not been stratified and analyzed in terms of special educator service settings. The sample size for this study also only represents a fraction of potential special educator voices. Likewise, the sample population represents a cultural bias in that they come from the western US, and although they come from various stations in the US school system, they cannot speak for voices outside that demographic. In addition, the participants were educated in US post-secondary 
schools. Future research needs to listen to a broader range of voices, including those across the nation and globally.

\section{References}

Brownell, M. T., Bishop, A. M., \& Sindelar, P. T. (2018). Republication of "NCLB and the demand for highly qualified teachers: Challenges and solutions for rural schools. Rural Special Education Quarterly, 37(11), 411. doi: $10.1177 / 8756870517749604$

Bruggink, M., Goei, S. L., \& Koot, H. M. (2016). Teachers' capacities to meet students' additional support needs in mainstream primary education. Teachers and Teaching: Theory and Practices, 22(4), 448-460.

Carroll, D. (2012). Examining the development of dispositions for ambitious teaching: One teacher candidate's journey. The New Educator, 8(1), 38-64.

Creswell, J. W. (2013). Qualitative inquiry \& research design: Choosing among five approaches. Los Angeles: Sage.

Cushner, K. H., McClelland, A., \& Safford, P. (2015). Human diversity in education: An intercultural approach. (8th ed.) New York: McGraw-Hill Education

Doulkeridou, A., Evaggelinou, C., Mouratidou, K, Koidou, E. Panagiotou, A., \& Kudlacek, M. (2011). Attitudes of Greek physical education teachers towards inclusion of students with disabilities in physical education classes. International Journal of Special Education, 26(1), 1-11.

ElSaheli-Elhage, R., \& Sawilowsky, S. (2016). Assessment practices for students with learning disabilities in Lebanese private schools: A national survey. Cogent Education, 3(1). doi: 10.1080/2331186X.2016.1261568

Feuer, M. J., Floden, R. E., Chudowsky, N., \& Ahn, J. (2013). Evaluation of teacher preparation programs: Purposes, methods and policy options. Washington, DC: National Academy of Education.

Flower, A., McKenna, J. W., \& Haring, C. D. (2017). Behavior and classroom management: Are teacher preparation programs really preparing our teachers? Preventing School Failure: Alternative Education for Children and Youth, 61(2), 163-169. doi: 10.1080/1045988X.2016.1231109

Forte, A. M., \& Flores, M. A. (2014). Teacher collaboration and professional development in the workplace: A study of Portuguese teachers. European Journal of Teacher Education, 31(1), 91-105. Doi: 10.1080/02619768.2013.763791

Friend, M. (2015). Welcome to co-teaching 2.0. Educational Leadership, 73(4), 16-22.

Friend, M., Embury, D. C., \& Clarke, L. (2015). Co-teaching versus apprentice teaching: An analysis of similarities and differences. Teacher Education and Special Education, 38(2), 79-87.

Grskovic, J. \& Trzcinka, S. (2011). Essential standards for preparing secondary content teachers to effectively teach students with mild disabilities in included settings. American Secondary Education, 39(2), 94-106.

Harper, C., \& de Jong, E. (2009). Using ESL teachers' expertise to inform mainstream teacher preparation. In C. Rodriquez-Eagle (Ed.), Achieving Literacy Success with English Language Learners: Insights, Assessments, and Instruction. (pp. 25-42). Worthington, $\mathrm{OH}$ : Reading Recovery Council of North America.

Harvey, L., (2019). Analytic quality glossary. Quality Research International. Retrieved from: http://www.qualityresearchinternational.com/glossary/

Ingvarson, L., Reid, K., Buckley, S., Kleinhenz, E., Masters, G., Rowley , G. (2014). Best practice teacher education programs and Australia's own programs. Canberra: Department of Education.

Jones, N. D., Youngs, P., \& Frank, K. A. (2013). The role of school-based colleagues in the shaping of commitment of novice special and general education teachers. Exceptional Children, 79(3). 365-383.

Kent, A. M., \& Giles, R. M. (2016). Dual certification in general and special education: What is the role of field experience in preservice teacher preparation? The Professional Educator, 40(2), 18-31.

Kirwan, J. R., \& Roumell, E. A. (2015). Building a conceptual framework for online educator dispositions. Journal of Educators Online, 12(1), 30-61.

Leko, M. M., Brownell, M. T., Sindelar, P. T., \& Kiely, M. T. (2015). Envisioning the future of special education personnel preparation in a standards-based era. Exceptional Children, 82(1), 25-43.

Merriam, S. B., \& Grenier, R. S. (2019). Qualitative research in practice: Examples and analysis. San Francisco: Jossey-Bass Publishers.

Mertler, C. A., (2014). The data-driven classroom: How do I use student data to improve my instruction? Alexandria, VA: ASCD.

Miskovic, M., \& Curcic, S. (2016). Beyond inclusion: Reconsidering policies, curriculum and pedagogy for Roma students. International Journal of Multicultural Education, 18(2), 1-14. 
Notar, C. E., Riley, G. W., Taylor, P. W., Thornburg, R. A., \& Cargill, R. L. (2009). Dispositions: Ability and assessment. International Journal of Education, 1(1), 1-14.

O'Connor, E. A., Yasik, A. E., \& Horner, S. L. (2016). Teachers' knowledge of special education laws: What do they know? Insights into Learning Disabilities, 13(1), 7-18.

Ozel, E., Zhagan, M., Nor, M. M., Kaud, M. A. K. M., \& Ali, N. A. B. N. (2017). The human right to inclusive education under international law: Mallaysian's concept. Journal of Global Business and Social Entrepeneurship, 1(3), 234-243.

Page, A., \& Davis, A. (2016). The alignment of innovative learning environments and inclusive education: How effective is the new learning environment in meeting the needs of special education learners? New Zealand Journal of Teachers' Work, 13(2), 81-98.

Pavlović, S. (2016). Inclusive school is (not) possible-Pupil's voice. Universal Journal of Educational Research, 4(11), 2502-2508.

Rock, M. L., Spooner, F., Nagro, S., Vasquez, E., Dunn, C., Leko, M., Luckner, J., Bausch, M., Donehower, C., \& Jones, J. L. (2016). 21 ${ }^{\text {st }}$ century change drivers: Considerations for constructing transformative models of special education teacher development. Teacher Education and Special Education 39(2), 98-120.

Rosenberg, J. M., \& Koehler, M. J. (2015). Context and teaching with technology in the digital age. In M. L. Niess, \& H. Gillow-Wiles (Eds.), Handbook of research on teacher education in the digital age (pp. 440-465). Harrisburg, PA: IGI Global.

Saloviita, T. (2018). How common are inclusive educational practices among Finnish teachers? International Journal of Inclusive Education, 22(5), 560-575. doi: 10.1080/13603116.2017.1390001

Sharma, U., \& Sokal, L. (2015). The impact of a teacher education course on pre-service teachers' beliefs about inclusion: An international comparison. Journal of Research in Special Educational Needs, 15(4), 276284.

Shevlin, M., Winter, E., \& Flynn, P. (2013). Developing inclusive practice: Teacher perceptions of opportunities and constraints in the Republic of Ireland. International Journal of Inclusive Education, 17(10), 1199-1133. doi: 10.1080/13603116.2012.742143

Smit, R., \& Humpert, W. (2012). Differentiated instruction in small schools. Teaching and Teacher Education, 28, 1152-1162. doi: 10.1016/j.tate.2012.07.003

Turnbull, A., Turnbull, R., \& Wehmeyer, M. (2010). Exceptional lives: Special education in today's schools (6th ed.). Upper Saddle River, NJ: Pearson.

US Department of Education, National Center for Education Statistics. (2012). Digest of education statistics (2011). Retrieved from http://nces.ed.gov/fastfacts/ display.asp?id=59

U.S. Department of Education. (2015). Every Student Succeeds Act (ESSA). Retrieved from http://www.ed.gov/essa 